\title{
Chapter 3 Working with and learning from cases
}

In this chapter we discuss the potential value of a case-based approach to teacher education, assuming that it may expand professional competences necessary to promote autonomy in schools by helping teachers to understand and explore teaching as a space of possibility. We will present the rationale of the approach as well as some relevant research studies focussing on its use, thus paving the way for the next two chapters, where we will present two different strategies that illustrate case pedagogy in language teacher development contexts.

\section{Professional development and the case method}

Enkenberg (2001) harshly criticises university education because the learning is usually separated from expert practice. This separation is tricky because expert practice is crucial to real-world performance and it is difficult to teach merely through explanation or lecture. When teacher education is merely transmissive, that is, skills and knowledge are taught abstractly, students experience difficulties in understanding their relevance in concrete, real-world situations. In addition, many student teachers will fail to see the relationship between teacher education and teaching. Teaching from whatever methodological standpoint requires a conception and personal understanding of it as well as the ability to think critically about it and to translate critical analysis into deliberate action. The production of meaning is therefore a necessary condition for the functioning of any social practice.

Professional development is a continuous process that is based on a critical understanding of the profession. It is about change: change in individuals, change in their perspectives and personal theories, and change in their practices. We agree with Cole's and Knowles' (1993) assumption that professional development encompasses a lifelong continuum of meaningful experiences from which teachers can learn and grow, both professionally and personally. Cases present specific concerns and dilemmas that raise questions and stimulate reflection. They provide the potential for making connections between the act of teaching and the cognitions and feelings that explain and motivate it. "They offer a vehicle for making tacit explicit” (Richert 1991a: 117) and for student teachers to become "scholars of their own practice" (Richert 1991b: 141). In turn, reflection involves a dialogical discussion with self and others. The process of reflection involves questioning what one believes to be true. In the reflective process, teachers are 
expected to reconceptualise cases in terms of their own experience. "Through the notion of effective reflective practice, it is possible to consider teacher knowledge through particular concrete examples" (Loughran 2002a: 39). Working with cases is a teacher education strategy that speaks to "the potential that humans possess for shaping not only the world, but themselves" (Eisner 2004: 10).

Suggestions for change and innovation in initial and in-service teacher education have derived from a growing understanding of the professional development of teachers, thanks to research agendas such as studies on teacher beliefs, novice/expert studies; investigations into teacher thinking and decision making; as well as research on teacher change. Research has also found evidence for the developmental nature of learning to teach (Richardson-Koehler 1985; Griffin 1987; Hunsaker and Johnston 1992; Cole and Knowles 1993; Harrington 1994). Accordingly, the philosophy and goals of teacher education programmes should address the needs of teachers at various points in their development. They have to learn to deal with the many teaching and learning dilemmas they will face in the course of their work. Because teaching is an "ill-structured domain" characterised by uncertainty and ambiguity (Spiro et al. 1987: 2), teacher education programmes cannot guarantee that teachers will understand the dilemmas of teaching merely through the presentation of techniques and methods. Because teaching is so complex and uncertain, learning to teach requires the opportunity to observe and to practise teaching from different perspectives:

In ill-structured domains, general principles will not capture enough of the structured dynamics of cases; increased flexibility in responding to highly diverse new cases comes increasingly from reliance on reasoning from precedent cases. Thus, examples/cases cannot be assigned the ancillary status of merely illustrating abstract principles (and then being discardable); the cases are key - examples are necessary, and not just nice. (Spiro et al. 1988: 7)

In addition, the highly context-dependent nature of teaching makes it necessary for teachers to examine principles applied in particular situations. To this end, we need to look for alternative strategies that will help these teachers develop conditional knowledge and a way of knowing that will actually reflect and tackle the complex, context-dependent nature of teaching as well as the moral embeddedness of teaching and learning (Reynolds 1989; Houston 1990; Harrington 1994). After studying a complex teaching problem in a medical school, Spiro et al. (1987) came to the following conclusion:

The best way to learn and instruct in order to attain the goal of cognitive flexibility in knowledge representation for future application is by a method of case-based representations which treats a content domain as a landscape that is explored by 'criss-crossing' it in many 
directions, by reexamining each case 'site' in the varying contexts of different neighboring cases, and by using a variety of abstract dimensions for comparing cases. (Spiro et al. 1987: 178)

Research has also shown that clinical and field experience components of preservice programmes are effective strategies to provide student teachers with this knowledge (Buchmann and Schwille 1983; Feiman-Nemser and Buchmann 1985; Houston 1990; Calderhead and Shorrock 1997; Darling-Hammond 2006b). Researchers in this field have also found that the construction of professional knowledge is nurtured and fostered by professional dialogue (Barnett and Ramirez 1996; Ingvarson and Marrett 1997; Schifter and Fosnot 1993; L. Shulman 1996). Furthermore, recent trends in cognitive psychology have acknowledged the importance of cognitive flexibility ${ }^{6}$ in ill-structured domains. Others similarly suggest that complex knowledge is best conveyed by its representation in multiple, context-dependent situations (Spiro et al. 1987; Spiro et al. 1988). Freeman and Johnson (1998) advocate a reconceptualisation of the knowledge base for language teacher education and argue that the core of the new knowledge base for teacher education must focus on the activity of teaching itself; it should be centred on the teacher who does it, the context in which the teaching takes place, and the pedagogy by which it is done.

Advocates of case pedagogy for teacher education have argued by analogy to case pedagogy in other fields of professional education. Actually, cases have a long history in the training of business, law, social work, and medical professionals. The origins of the case method are to be found in the field of law and in the work of cognitive psychologists and curriculum theorists (Merseth 1991a,b). According to Merseth (1991b), it was Christopher Columbus Langdell, first dean of the Harvard Law School, who proposed the case method in legal education precisely because he believed that cases could become the most powerful medium for teaching theory. From J. Shulman's (2002) perspective, the use of cases draws on the tradition of business school cases which are researched-based, problemfocused narratives of authentic events, crafted to motivate analysis and discussion about the problems that business school students are expected to face when they graduate (Christensen, Garvin, and Sweet 1991), but is also influenced by Jerome Bruner's distinction between paradigmatic and narrative ways of knowing. The former takes the form of principles, which is the kind of knowledge that social

6 Cognitive flexibility refers to the capacity to restructure knowledge in multiple ways depending on changing situational demands (i.e. difficulty or complexity of the situation). The ultimate goal of cognitive flexibility is to help develop learners' ability to understand different situations (Graddy 2001). 
scientists generate from their research. But principles alone cannot inform good teaching. Knowledge is more situated and often takes the form of good stories.

Doyle (1990) claims to have found evidence of the use of case pedagogy in teacher education as early as 1864. McAninch (1991) also mentions several predecessors of recent casebooks. Nevertheless, research concerning the impact of case pedagogy in the education of teachers did not really start until the late 1980s. In the two following sections we highlight potential uses and gains of a case-based approach to teacher development.

\section{What is a case and how can cases be used?}

Grossman (1992) wonders whether cases are instances of theory exemplifying theoretical learning, or whether they are instances of practice from which one can learn about teaching. These and other questions surround the use of cases in teacher education.

L. Shulman (1992: 3) maintains that a teaching case is a "description of episodes of practice, a selection of reality, a slice of life, a story designed and presented as study material, an exercise, a puzzle, or a problem.” Barnes, Christensen and Hansen (1994: 44) define cases as a "partial, historical, clinical study of a situation that is usually presented in narrative form to support student involvement, it provides data-substantive and process-essential to an analysis of a specific situation, for the framing of alternative action programs, and for their implementation recognizing the complexity and ambiguity of the practical world.” Lynn (1999: 42) also gives the following definition: "A teaching case is a story, describing or based on actual events and circumstances, that is told with a definite teaching purpose in mind and that rewards careful study and analysis."

By and large, cases describe complex situations that can be used in learning about professional practice (Richert 1991a). A case typically includes the perspectives and feelings of the case teacher/writer as he or she describes a series of events. A case is supposed to be rich with detail and dialogue about the quandaries and challenges reported (Shulman and Sato 2006). Cases can also include reflective comments by the author and/or teacher. All this material is intended to raise questions about critical issues in teaching; otherwise cases are of little value. In addition, cases have to be representative of classroom dilemmas, problems, or obstacles. Therefore, an effective case is not just a story; rather a good case has as its goal the coherent presentation of rich data. A case relates an event - or series of events - that contains enough perplexities and critical incidents to encourage a rich educational discussion. Most importantly, a case 
is expected to be a "case of something", which means that it should illustrate concrete realisations of general ideas or principles that may apply to other cases (L. Shulman 1986a: 11). Effective cases should weave together learning about the knowledge, skills and dispositions that form part of teaching by creating the conditions for teachers to practise 'thinking like a teacher' (Kleinfeld 1992; Zeichner and Liston 1996).

On working with a case, we enter the experience of others and make links to our own experience, using both as lenses through which to look at our future work. In doing so, we question pedagogical practices, look at them from various angles, uncover the personal theories they embody, and confront those theories with alternative views. As L. Shulman puts it, "every case, in its particularity, derives its 'case-ness' from its connection to other cases and to organising theories and principles" (2004a: 479). Many teacher educators nowadays share the hope that L. Shulman enunciated about cases and case pedagogy when he wrote:

I envision case methods as a strategy for overcoming many of the most serious deficiencies in the education of teachers. Because they are contextual, local, and situated - as are all narratives - cases integrate what otherwise remains separated... Complex cases will communicate to both future teachers and laypersons that teaching is a complex domain demanding subtle judgement and agonizing decisions.” (L. Shulman 1992: 28)

Sykes and Bird (1992: 466) classify the use of cases into four distinct approaches, including their associated conversations and approach to reasoning ${ }^{7}$ :

- The foundational approach emphasises theory, regarding teaching as a matter of applying theory to practice. Cases in this category typically try to exemplify or illustrate different instances of theory. Sykes and Bird (1992) argue that teacher education in the USA has traditionally over-emphasised this approach. They argue that teacher education has systematically valued theory over practice, arguing for an exploration of all of the different types. This approach to cases does not assume any direct relationship between theory and cases but aims to cultivate analytic skills in the application of

7 Sykes and Bird (1992: 466) present four types of "conversation and reasoning” that they consider might be desirable in teacher education and in teaching. These identify four types of community of practice. The first kind of conversation focuses on theory and regards teaching as the application of theory to practice. Cases are regarded as instances of theory. The second one is also concerned with the relationship between theory and practice but reverses the emphasis, assigning greater relevance to situated problems of practice. Cases in this community are used to stimulate deliberate and reflective action. The third kind of community uses stories and alternative narrative modes of communicating and knowing. The fourth one is similar to the tradition of moral casuistry. Members of this community would reason from case to case by analogy, using cases as a body of knowledge. 
ideas and to convey theoretical knowledge about teaching in a form that will be useful to the interpretation of situations, the making of decisions, the choice of actions, and the formation of plans and design, that is, it seeks to promote a strategic understanding (L. Shulman 1986b).

- The pragmatic approach highlights practice, giving teachers the opportunity to think like a professional through vicarious experience. Cases in this category describe situated teaching problems that are used for deliberation and reflection, often aided by theory. In this approach, professionals deliberate on a case and the teaching issues it presents, using research findings, theory, and principles to make sense of the case. "Through case deliberations students develop a proper appreciation for the value of theory, learning its uses in wise, self-reliant ways" (Sykes and Bird 1992: 471).

- The narrative approach relies on narrative accounts of teaching, usually in the absence of theory. The surging interest in cases stems from an increasing appreciation of the value of "narrative" forms of thinking as opposed to abstraction and generalisation (Bruner 1986). "The conclusions of much formal research on teaching”, Bolster (1983: 295) points out, “appear irrelevant to classroom teachers - not necessarily wrong, just not very sensible or useful.” Furthermore, narrative inquiry is receiving increasing support from research in teacher education (Clandinin 1986; Clandinin and Connelly 1996; Connelly and Clandinin 1990, 1995; Conle 2001). Central to learning from narratives is the use of "multiple frameworks composed of concepts, ideas, and values" (Sykes and Bird 1992: 473). As L. Shulman suggests (2004a: 474), "to assert that a narrative is a case is to engage in an act of theory": it requires teachers to connect the narrative to personal/ other experiences, that is, to other cases, and also to "categories of experience, to theoretical classifications through which they organise and make sense of their world" (L. Shulman 2004a: 474). Narratives provide powerful advantages in simulating and representing complex, multidimensional realities. Sykes and Bird (1992) hypothesise that reading rich narratives may help prospective teachers to gain the understanding they need in teaching. Narrative forms of thinking seem to be far more compatible with the ways teachers actually organise their experiences and develop professional knowledge. Stories point toward deep beliefs and assumptions that people often cannot convey in propositional or denotative form, that is, the 'practical theories' and deeply held images that guide their actions (Mattingly 1991). Schön $(1983,1987)$ has argued that much practical knowledge is tacit. The value of stories, Nymark (2000) argues, resides in their capacity to tap into the unconscious qualitative phenomena that pervade organisations. 
- In the casuist approach the basis for viewing reports of experience as cases comes from a regard for the 'storied' nature of knowledge (Carter and Anders 1996). Cases are considered a body of knowledge in themselves. Members of a community share precedent cases and compare them without resort to theory, exploring and counterbalancing critical incidents from the classroom, which encourages them to identify similarities and differences, "to reason from case to case, and to create a set of cases to which they can refer as they gain new knowledge - all features of casuistic case study" (Jay 2004: 47). Grossman (1992) argues that teachers tend to think and talk in terms of stories, which is a common way to organise knowledge in ill-structured domains (Spiro et al. 1987). Teaching represents one of these ill-structured domains characterised by uncertainty and ambiguity. Some argue that the casuist approach helps "organize ... knowledge of teaching and serve as precedent cases from which [to] reason about current dilemmas” (Grossman 1992: 232).

In a review of the use of case pedagogy, Kagan (1993) has identified three different uses: (a) as instructional tools to help novices connect theory to practice and develop problem-solving skills (L. Shulman 1986b); (b) as instruments of research on teacher cognition (Kagan and Tippins 1993; Calderhead and Shorrock 1997; Moje and Wade 1997); and (c) as catalysts for stimulating change in teachers' pedagogical beliefs and practices (Carr and Kemmis 1986; Carter 1988; L. Shulman 1992). These three approaches to case-based pedagogy adopt different working perspectives. However, they all reflect a notion of learning to teach as a contextualised local activity, embedded in a particular context, time and space, and affected by numerous field dilemmas that teachers face in their teaching practice (Moje and Wade 1997).

L. Shulman (1986b) suggests that in pre-service teacher education cases are mainly used to exemplify theoretical principles, maxims and norms. Hence, the selection of teaching cases is thought to be an essential component in a teacher education programme that aims at preparing teachers for the complex task of teaching, providing context-bound knowledge of specific critical incidents and problems that they will face (Carter 1988; Harrington and Garrison 1992). In in-service teacher education programmes, a more narrative tradition seems to underlie the use of cases as catalysts for professional development and to encourage innovation (Kagan 1993). This perspective supports the notion that knowledge can be inferred and developed from narratives, stories, accounts and images teachers have of their teaching, as portrayals of their teaching world and of the knowledge used as a basis for action (Elbaz 1983; Bruner 1986; Rosen 1988; Connelly and Clandinin 1990). 
Different approaches to case pedagogy have points in common and can be combined, not only for case analysis but also for case construction, which is not so emphasised in the literature. Actually, teachers can build cases by designing, developing, evaluating, and narrating pedagogical experiments. All these processes entail the interrogation and transformation of personal theories and practices, the theorisation of teaching and learning processes, and the exploration of a language of experience for writing about their practice (see Vieira 2009b, 2010b, 2011b). This approach will be illustrated in chapter 4. Moreover, teacher educators can collaborate with teachers to build cases from their experience and present those cases not as narratives but as multimodal texts where different resources are combined (e.g. short narratives, reflective tasks, teaching materials, classroom data, classroom videotapes, and theoretical information). These cases are specifically constructed to be used by other teachers so as to promote reflectivity and innovation (see Jiménez Raya 2011b; Jiménez Raya and Vieira 2011). This second approach will be illustrated in chapter 5 .

\section{Reasons for the use of cases in teacher education}

There are a considerable number of publications that argue that the effects of teacher preparation programmes fade away as soon as student teachers graduate and start teaching (Lortie 1975; Zeichner and Liston 1987; Zeichner and Tabachnik 1981; Zeichner, Tabachnik, and Densmore 1987). In the 1990s, as part of a call for encouraging reflective practice, several theorists proposed the case method as a way to nurture reflection while minimising problems associated with field experiences (L. Shulman 1987; Carter 1988; Merseth 1991a; J. Shulman 1992; Harrington 1995). Many teacher educators have argued for the use of case pedagogy in pre-service and in-service teacher education (Greenwood and Parkay 1989; Christensen 1987; Shulman and Colbert 1989; Doyle 1990; Florio-Ruane 1990; Merseth 1991a, 1996; Richert 1991a, 1991b; Sykes and Bird 1992; J. Shulman 1992; McAninch 1993; Barnes, Christensen, and Hansen 1994; Barnett 1998; Kinzie, Hrabe, and Larsen 1998; Darling-Hammond and Sykes 1999; L. Shulman 2004a; Vieira 2009a; Jiménez Raya 2011b; Jiménez Raya and Vieira 2011). Two factors have stimulated the interest in case pedagogy in teacher education. The first is connected to the nature of teacher knowledge, springing from recent work on constructivist approaches to teacher education, teacher knowledge, and teacher cognition. Second, appeals for the reform of teacher education bolster the use of alternative methods in teacher education programmes. 
Furthermore, various researchers believe that it is somehow possible to capture the relationships between teacher actions and student outcomes and make it available for teachers ${ }^{8}$ (Berliner and Rosenshine 1976; Brophy and Good 1986; J. Shulman 1992; Goldblatt and Smith 2004). Another trend of research in teacher education suggests that teachers do not operate from a set of theories or principles, but rather they build multiple strategies for practice through experience in contextualised situations. Recent research on teacher thinking highlights that knowledge is context-specific, non-fixed and continually evolving (Clark and Lampert 1986; Clark and Peterson 1986; Calderhead 1987). Accordingly, teacher activity derives from induction from multiple experiences, not deduction from theoretical principles. Rather than acting deductively, they do it inductively, grounding their actions on experience. These researchers maintain that teachers are professionals who make decisions and plans grounded on principled knowledge that they adapt to the particulars of their teaching context. Other researchers on teacher knowledge suggest that skilful teachers create multiple scripts from experience in contextualised situations. Many of the concepts that are part of teacher education for learner autonomy, such as "autonomy," "metacognition," "active learning," "autonomy support," "self-regulation," "learning to learn," or "cooperative learning” are indexed to situations of use in classrooms. From the perspective of sociocultural theory, this means that such concepts are best learned in the context of authentic activities in schools and classrooms. The implication is that for these concepts to become part of the teachers' working vocabulary and repertoires, theoretical knowledge needs to be bonded to situations of use, and this insight leads logically to an interest in apprenticeship and simulations as well as other forms of field experience. Cases are then expected to constitute learning tools within field experiences.

Traditionally, teacher education has held contrasting interpretations regarding the appropriate roles for theory and practice in teacher education. Dewey (1965) deemed this dichotomy as particularly inappropriate in a professional field such as teaching. Debates and tensions have been a permanent feature in teacher education theory. In teaching, theory and practice are two faces of the same coin rather than dichotomous realities. Learning to teach is a complex developmental process that is facilitated by participation in the social practices associated with teaching (Jiménez Raya 2009). Accordingly, the mere demonstration of the behav-

8 Leinhardt (1988) contends that a well-researched, wisely annotated library of videotaped expert lessons (i.e. cases) would be extremely helpful to novices in "building a rich taxonomy of lesson scripts that are known to be successful". This way cases would be employed to display well-articulated classroom processes for modelling and emulation, rather than provide material for inquiry. 
iours associated with teaching will not necessarily result in measurable and socially significant changes in student teachers' behaviour. Teaching is a socially constructed activity that requires the interpretation and negotiation of embedded meanings within the classrooms and schools where teachers teach. The acceptance of this assumption also implies that teachers' knowledge is constructed by teachers themselves, and that it is mainly experiential. Accordingly, theory will only inform classroom practice to the extent to which teachers can make sense of the theory (Fenstermacher 1986). Nonetheless, theory is a necessary component of professional development because theoretical resources provide ways for teachers 'to think outside taken-for-granted frames'.

Clark and Lampert (1986) call for a conception of knowledge of teaching that goes beyond the polarising views presented above. They maintain that teachers need contextual knowledge because their decisions are situation-specific. Thus, the "specificity and localism of cases as instructional materials may not be problematic for learning; indeed they may be far more appropriate media for learning than the abstract and decontextualised lists of propositions or expositions of facts, concepts, and principles" (Clark and Lampert 1986: 24). Knowledge of teaching is also interactive. Teachers pose questions to students, expect responses, and watch for signs of understanding. For them, teacher knowledge is also speculative as there is a great deal of uncertainty caused by the multitude of constantly-competing hypotheses about it.

The purposes of the case method in teacher education for learner autonomy must take into consideration the nature of the body of knowledge available in the professional field of modern language teaching, a body of knowledge that is not well-defined or completely codified. Teaching is a profession that is organised around human interaction and strongly influenced by specific contexts. The potential of cases resides precisely in that they can help teachers to apply teaching principles and even to devise new ones, as teachers are often expected to achieve “...complex and even conflicting goals. Under these circumstances, a priori knowledge identified by researchers about the relationship among particular decisions or actions and their outcomes is of limited worth" (Clark and Lampert 1986: 28).

Teachers' knowledge about teaching is not merely an extended body of facts and theories but it is instead largely experiential and socially constructed out of the experiences and classrooms from which they have come. Van Manen (2003: 16) argues that practical knowledge exists in the teaching situation of the classroom, a kind of "felt sense of the classroom" and not primarily in the intellect of the head. Cases offer the possibility of integrating knowledge from research and teachers' craft knowledge in a way that is useful and relevant to other teachers because of their close connection to the genuine processes of teaching and 
learning that actually occur in classrooms (Jiménez Raya 2009). From this point of view, knowledge about teaching is not separate from actual practice; it is coextensive (Lather 1986). In addition, a consequence of generating knowledge that is linked to practice is that it is detailed, concrete, and specific.

Over the last three decades, the field of teacher education has struggled to extend Dewey's ideas to the development of research programmes and adult education curricula based on the notion of 'learning from experience'. These programmes are developed on the premise that teacher learning is more effective when it is relevant to teachers' vicarious experiences (Stake 1988), to their everyday dilemmas, concerns and stages of professional development (Hunt 1978; Brundage and MacKerarcher 1980; Feiman-Nemser and Floden 1981; Fessler 1985; Elbaz Luwisch 2001), when there is a focus on both theory and practice (AbdalHaqq 1998; Sykes and Bird 1992; Carter 1993; Carter and Anders 1996; DarlingHammond and Sykes 1999), when it encourages reflective inquiry (Schön 1983, 1987, 1991; Richards and Lockhart 1994; Zeichner and Liston 1996; Akbari 2007) and when it allows for teachers to share their experiences with other colleagues in supportive and conversational frameworks (Florio-Ruane 1991; Clark 1995; Connelly and Clandinin 1995; Rust and Orland 2001; Bausmith and Barry 2011).

Kleinfeld (1992) argues that teacher education cannot offer teachers clear rules "for navigating through the terrain" (p. 40). What teacher education can do is to help teachers develop the ability to think clearly about the complex empirical and normative questions they will face in various teaching situations. Because teaching is a highly context-dependent activity, it is only possible to hint at a few of the crucial issues and dilemmas in pedagogy for teacher and learner autonomy. Teacher education can also help (student) teachers focus on the features of the situation they may want to attend to. It can further offer them research knowledge and practical examples of both successful and unsuccessful language teaching that may be helpful. But, in the final analysis, they will be on their own.

The literature on the use of the case method in teacher education highlights numerous advantages (L. Shulman 1989; J. Shulman 1992; Sykes and Bird 1992; Carter and Anders 1996). Some of them are: cases help (student) teachers discover what they know and believe about teaching and learning (Parker and Tiezzi 1992: 86); cases present an alternative to learning in the field (Richert 1991a); cases help prevent learning pitfalls in the context of practice (Feiman-Nemser and Buchmann 1985); cases act as a bridge between the abstract nature of principles and of teaching standards and classroom practice (L. Shulman 1996; Shulman, Whittaker, and Lew 2002); cases give teachers "a stock of educational strategies for use in analogous problem situations" (Kleinfeld 1992: 35), “illustrate approaches, and encourage problem-solving” (Carter and Anders 1996: 578). Case pedagogy also changes the focus of learning away from the simple memorisation 
of facts to the application of theory, concepts, and techniques to practical, real world problems, fostering active, experiential, responsible learning by involving teachers in their own development process (Christensen, Garvin, and Sweet 1991; Gallagher, Stepien, and Rosenthal 1992; Albanese and Mitchell 1993; Carlson and Schodt 1995). As Merseth (1991a) writes, cases convey the message that teaching is complex, contextual and reflexive.

Advocates of this instructional method contend that cases contribute to making pedagogic learning relevant and meaningful to teachers through the active participation in the analysis, discussion and solving of real problems in learning to teach (Carlson and Schodt 1995; Levin 1995; Tillman 1995; Erskine, Leenders, and Mauffette-Leenders 1998). In addition, cases can be viewed as (L. Shulman 1992: 2):

1. Creating or increasing motivation for learning

2. Providing unique benefits to practitioners who participate in writing as case authors or commentators

3. Supplying specific antidotes to the dangers of overgeneralisation from either the learning of principles or from prior cases.

4. Serving as the instructional material around which participants can form communities for discussion or discourse.

Discussion pedagogy is said to offer substantial advantages when the educational goals are critical thinking, autonomy, problem-solving, and the development of qualities such as sensitivity, cooperation, and zest for discovery (Barnes, Christensen, and Hansen 1994). The achievement of these complex, value-laden instructional goals entails that both teacher educators and teachers modify their traditional roles and responsibilities. The case method requires a teacher educator to be guide, tutor, coach, or facilitator, a role repeatedly advocated by proponents of participatory learning (Wilkerson and Feletti 1989; Aulls 1998; Erskine, Leenders, and Mauffette-Leenders 1998).

There are at least three different purposes for using cases:

a) cases as exemplars (i.e., to exemplify principles)

b) cases as opportunities to practise analysis and to contemplate action (i.e., to practice decision-making and problem-solving)

c) cases as stimulants for personal reflection (i.e., to encourage teachers to reflect on practice, often with teachers writing their own cases) (Merseth 1996).

The arguments for the use of cases in teacher education are abundant and wisely grounded in theory. Yet, some of the claims have not been tested empirically. Research on case pedagogy is still scarce, particularly in teacher education for 
learner autonomy. There are, however empirical studies that have investigated the potential of cases for professional development and teacher learning. In the following section we briefly present some of those studies.

\section{Research on the use of cases in teacher education}

As we have commented in the previous sections, teacher education has expressed a tremendous enthusiasm for case pedagogy. The spread of case pedagogy in teacher education and the appeals for the need to conduct research to validate the numerous claims made on the benefits of its use have motivated a number of research projects to investigate its potential for professional development and teacher learning. Initially, research tried to conceptualise case pedagogy by focussing, according to L. Shulman (1992) and Sykes and Bird (1992), on theoretical discussions around epistemological and methodological issues and implications of case pedagogy for teacher learning (see also Merseth 1991a; Lynn 1999). This research strand has produced valuable insights; however, the need for empirical research is still a pressing matter. Carter (1990: 307) also recommended that studies on teachers' knowledge pay more attention "to the substance of what teachers... know about classrooms, content, and pedagogy”. Moje and Wade (1997) voice a similar claim. They suggest that we need to learn more about "what case methods mean for teachers' thinking, how teachers think and reason about teaching via teaching methods and case discussions" (p. 692).

One of the gains of case-pedagogy refers to the articulation of theory and practice. In a project conducted by Welty and Kaufman in two educational psychology courses ${ }^{9}$, the researchers gave students in the two courses, one casebased, one lecture-based, the same case to analyse in writing at the beginning and the end of the course. Using content analysis, they looked for evidence of students' ability to link theory with practice. They found significant evidence that students in the case-based class could apply theory to teaching situations much more readily than their peers in a lecture-based educational psychology course. All students in the case-based class were able to use applicable theory, while only half of those in the lecture-based class were able to. Similar results were obtained by Bruning et al. (2008), who conducted two studies in multisection introductory child and adolescent development classes to determine effects of the intro-

9 "Using Case Method to Link Theory and Practice in Two Educational Psychology Courses", in http://www2.ed.gov/about/offices/list/ope/fipse/lessons3/pace.html 
duction of abbreviated teaching case studies that were then discussed either in face-to-face or online formats. Their general goal was to experimentally examine whether a case-based teaching approach improved students' ability to think critically about educational issues depicted in case studies and warrant their thinking by application of psychological constructs. Students receiving teaching case studies in either format in both classes showed improved ability to critically analyse cases compared to control participants. Both case study groups in the child development class also showed increased application of psychological concepts in analysing new cases. The authors interpreted the results as supporting a case analysis approach in educational psychology classes and the use of online methods for presentation and discussion of abbreviated cases.

Another major outcome of case pedagogy appears to be the enhancement of critical abilities. Kleinfeld (1989, 1991) demonstrated that teaching with cases helps students to understand the meaning of events, increase their ability to frame educational problems, and improve their thinking regarding alternative courses of action. The development of critical abilities is also documented by Harrington, Quinn-Leering and Hodson (1996) after studying the case analyses of 21 students. Their results show that case pedagogy contributes to the development of three elements of critical reflection: the ability to identify and acknowledge different perspectives (open-mindedness), the ability to consider the moral and ethical consequences of choices (responsibility), and the ability to identify and clarify the limitations in one's assumptions when making decisions (wholeheartedness). The role of cases in enhancing student teachers' ability to deal with dilemmas was investigated by Welty, Silverman, and Lyon (1991) in a qualitative research project to examine the extent to which cases help students appreciate a broader range of perspectives in certain educational dilemmas. They used content analysis of student papers as the primary research technique and found that, over time, students became more analytical in their approach to problems, were more likely to evaluate a variety of solutions rather than being satisfied with one right answer, were more open to their fellow students' ideas, applied theory to support their ideas, and displayed more satisfaction with the quality and quantity of their learning in their case-based course. Another study focused on educational dilemmas was developed by Cherubini (2009). He reports on a qualitative constructivist research study employing case-based pedagogy to investigate how Education undergraduate students made sense of the complex dilemmas inherent in the cases and in particular, the factors that exerted an influence on their critical thinking processes. In the study, Cherubini identifies three core categories that emerged from the data, including participants' evolving sense of self-confidence, their priority to maintain social cohesion over individual student outcomes, and participants' willingness to challenge taken- 
for-granted stereotypes. Further, he discusses the process of participants' engagement as they reflected upon the complexities of each case to arrive at new levels of awareness regarding their professional conduct, responsibilities, and behaviour in view of the Standards of Professional Practice. Kleinfeld (1991) also documents the role of case methods in the development of students' skills in spotting the issues in an ill-structured domain, framing the problems in productive ways, understanding the conflicts from the perspectives of different actors, and developing problem-solving alternatives. Kleinfeld studied two classes. In one she used cases and in the other she used discussions of practical examples and readings. The researcher studied mid-term examinations that included cases for analysis, classroom observations, an attitudinal survey, and the standard evaluation process. Based on the analysis of the data, she established that "students taught by the case method approach showed significantly greater ability to analyze an educational problem" that the students in the control group.

L. Shulman (1992) holds that the power of case pedagogy rests primarily in the content of the case, and not in how it is used in teacher education (e.g., it is lectured about, discussed, or simply read). For example, dilemma-based cases appear to be particularly useful in the development of reasoning skills. Harrington (1995) conducted a study to investigate this hypothesis and defined pedagogical reasoning in terms of five skills: problem identification, considering multiple perspectives, warranting solutions, consideration of consequences of proposed action, and the reflectiveness of students' critique of their analysis and solution for the case. Student teachers were asked to identify and discuss in their written case analyses the issues in the case; how they would prioritise the issues; based on that, what it was a case of; what the different perspectives on the issues were; what the educator's solution should be; what the possible consequences to that solution might be; and how they would critique their solution and analysis. Her findings suggest that the developmental nature of learning to teach is reflected in students' analyses of events embedded in cases and that dilemma-based cases provide opportunities to further encourage the development of professional reasoning in prospective teachers.

Nonetheless, other researchers contend that the value of case pedagogy is in the discussion process itself, rather than in the content of the case (Welty 1989; Merseth 1991b; Richardson 1991; Barnes, Christensen, and Hansen 1994; Flyn and Klein 2001). A study was conducted by Levin (1995) to investigate whether discussion is a crucial variable in teachers' learning from cases, by looking at what teachers understood from just reading and writing about a case, compared to what they thought when also discussing it. She used quantitative and qualitative analyses of participants' writing and oral discourse from the case discussions, and examined the quality, form, and content of the thinking of 8 student teachers, 
8 beginning teachers, and 8 experienced teachers. According to the findings, discussion appeared to act as a catalyst for reflection for highly experienced teachers; in the case of less experienced teachers and student teachers, discussion appeared to allow them to clarify or elaborate their understanding and increase their perspective on the issues in the case; in the control group (only reading and writing about a case), teachers reiterated their original thinking about the case, rather than gaining new perspectives.

The potential of case discussion was also investigated by Moje and Wade (1997). Drawing on sociocultural theories, they examined teacher thinking during case discussions in two university content literacy courses. Their purpose was to understand the sociocultural and semiotic tools pre-service and in-service teachers use to mediate and construct images and issues of teaching related to the teaching of literacy. Their findings indicated that case pedagogy has the potential to help teachers reflect on practice and explore other important issues in teaching. Their research further supported the claim that cases can serve as tools for mediating thinking about teaching. Combined with structured field experiences (Kagan 1992), they may represent a way to familiarise student teachers with potential students and secondary school classrooms, while encouraging them to move beyond technical rationality towards critical and reflective thinking about school education (Grossman 1992; Calderhead and Gates 1993). On the basis of their study, Moje and Wade recommend that cases be carefully crafted as tools to both highlight and challenge teachers' assumptions about learning and teaching.

The role of cases in providing rich and active learning environments is underlined by Grabinger (1996), who states that cases allow students to construct knowledge in an authentic environment, work cooperatively to produce something of real value, and assume personal responsibility for learning. However, the gains from case-pedagogy seem to vary depending on the interaction patterns that are promoted in case discussion. For example, Dröge and Spreng (1996) compared student-led and instructor-led case analysis methods that focused on both process and output by dividing responsibility among 'presentation,' 'solution,' 'critique,' and 'hand-in' student groups. They found that students perceived that the student-led case class was superior in terms of career preparation, use of time, satisfaction, involvement and achievement of educational goals (such as understanding the material) and specific skill competencies (such as oral skills). Another study conducted by Griffith and Laframboise (1997), based on a qualitative analysis of small- and large-group case discussions, showed that even though student discussions were based more on personal experiences than on theory and course content, more meaning was constructed during small group discussions during which the group reached consensus. This was not the case in large group discussions. Small group case discussion also seems to be more productive 
than individual work with cases. Flyn and Klein (2001) developed a study where a group of college students completed two cases either individually or in small discussion groups. Measures included two case analyses, time on task, an attitude survey, and document analysis. The results revealed significant performance and time differences between instructional methods on the first case, but not on the second case. In addition, results indicated significant differences in student attitudes between treatments. Generally, participants who worked in groups liked their method considerably better than those who worked alone, felt they learnt more working in a group than they would have working alone, and expressed a preference for working in a group if they had to do the class over again. Collaboration in case analysis can also involve team competition, as is documented by Kinzie, Hrabe, and Larsen (1998). They report on the design and use of a Webbased instructional design case in a team case competition in which six universities participated. Their research showed that team collaboration and competition were regarded as motivating factors by students.

One of the advantages of case pedagogy is the enhancement of teachers' pedagogical content knowledge. In exploring this potential, attention is drawn to subject-specific aspects of professional development and expertise. Barnett (1991) used the cognitive flexibility and knowledge transfer theory proposed by Rand Spiro and colleagues to frame the design of a case-based curriculum for use in mathematics teacher education. The paper includes an analysis of four discussions based on a case. The analysis also shows the potential of subject-specific cases for enhancing mathematics teachers' pedagogical thinking and reasoning. Barnett (1991: 263) declared that "by prompting mathematics teachers to frame problems, analyse situations, and argue the benefits and drawbacks of various alternatives, cases can play a critical role in expanding and deepening pedagogical content knowledge." Barnett and her colleagues have carried out extensive research to determine the usefulness of cases in the expansion of pedagogical content knowledge (Barnett 1991; Barnett and Tyson 1993a, 1993b). They started exploring the ways in which experienced and novice teachers responded to cases on mathematical topics such as rational numbers. They found that, unlike veteran teachers, novices emphasised pedagogy less than content. They argued that case discussions were "nevertheless helping them construct pedagogical content knowledge" (Barnett and Cwirko-Godycki 1988: 30).

Some studies on case-pedagogy investigate potential uses of teacher-written cases in professional development. For example, a study by Barnett (1998) focuses on a professional development process that uses teacher-authored cases (narratives about actual classroom experiences) as a stimulus for discussing mathematical, pedagogical and philosophical concepts and issues. The author studied how specific aspects of the cases and the case discussion process contrib- 
ute to a climate that is conducive for motivating increasingly informed and strategic inquiry. The results focus on four essential areas: (1) development of one's own understanding of mathematics; (2) use of the student perspective as a source of feedback; (3) a recast of the familiar as strange and the simple as complex; and (4) critical examination of alternative views and ideas. The author concludes that the Mathematics Case Methods Project demonstrates the remarkable value of collective inquiry and critical reflection. In particular, according to Barnet, the study illustrates how collective inquiry provides the chance to co-generate ideas that might not otherwise emerge through individual reflection or even by sharing ideas among several individuals. Barnet further claims that their work also shows how inquiry can become informed through the public scrutiny of ideas, which helps to reveal holes, blind spots, incongruences and mistakes in thinking.

Another approach to the use of teacher-written cases can be found in OrlandBarack's (2002) qualitative study to examine mentors' interpretations of their practice as revealed through writing and discussion of their cases in a university postgraduate course in Israel. The author adopted an interpretive stance to inquiry into the cases written by 15 in-service mentors who participated in a university postgraduate course on mentoring. The findings draw primarily on data from the written cases, supported by Orland-Barak's field notes of the discussions during the debriefing sessions, and participants' written reflections submitted to the course professor at the end of the course. The data was examined for emergent features of the practice of in-service mentoring in the Jewish and Arab sectors within the Israeli school system. Content analysis of the cases and of the discussions that followed their presentation in class revealed a unique 'discourse of mentoring' or 'language of practice' that reflected mentors' concerns over issues of accountability and boundaries of roles in their practice. The study reveals, from a programmatic perspective, that a university teacher education course based on case pedagogy constitutes a safe and challenging context for mentors to voice dilemmas inherent in their field experiences that are often silenced by the system.

Goldblatt and Smith (2004) also used teacher-written cases, claiming that their discussion altered teachers' views. Their study focused on an experiment with case work, in which 18 teachers wrote narratives describing their professional dilemmas. Through reflection and collaborative group work these practitioners co-created a set of cases, mapping them back to the standards in order to ascertain how the standards had been embedded or absent from their daily practice. To validate the effectiveness of the method, they used the cases in pre-service, in-service, principal and supervisory personnel venues. They also recorded the impact of the 'case institute' in a focus group session with the original writers. They contend that reflecting on dilemmas exposed personal theories, values 
and ethics. Furthermore, teachers' deeply seated contentions were challenged through deliberation on the complexity of teaching problems. Opposite interpretations of the same situation resulted in participants looking critically at themselves. Their conclusion is that cases were effective, reliable and valid catalysts in teacher education. Repetitive themes along with the replication of statements in participant observations confirmed the reliability of cases as a useful methodology. They argue that their research substantiated the importance of cases in terms of teaching teachers about standards, developing and reinforcing identity.

Haley (2004) presents the case study of one intern student teacher involved in his 15 -week experience in a linguistically and culturally diverse secondary school setting and how his case was used in a foreign/ second language methodology course. Haley examines the extent and nature of the student's critical reflections in determining the basis of sound methodological and pedagogical approaches to second language instruction. The author claims that the study demonstrates benefits of its use in one particular teacher education program. Additionally, Haley highlights, within the case study, the use of reflection and the creation of the professional development portfolio. Results indicated that the case-based method can be a valuable instructional tool in a methods class. Haley claims that students studying this case in the teacher education program discovered that they were able to link theory to practice and could understand and use educational theories and principles in becoming effective language educators.

The only study we found that is explicitly related with teacher autonomy was conducted by Barnett and Tyson (1993a). They investigated how case discussions support teachers' professional development by shifting their perception of authority from external to internal and collective sources. The primary data included transcripts of case discussions and interviews, as well as mathematics assessments of teachers. The findings demonstrated, according to the authors, that case discussions provide opportunities for: realising that capability and wisdom exist within the group; developing a critical stance; and developing stronger, more refined content and pedagogical content knowledge. The authors claim that teachers that capitalise on these opportunities have a richer sense of their own autonomy.

The studies presented above show various benefits of case pedagogy in teacher education. On the basis of this selective literature review we can assert that case pedagogy offers a promising opportunity for teacher educators to explore more effective pedagogies in teacher education. To develop our understanding of case pedagogy in teacher education for learner autonomy the teacher education profession needs to engage in empirical research as well as in case development and exploration. As in research on education in general, research on case pedagogy in teacher education for learner autonomy will have to consider the student- 
curriculum-teacher triangle. When we focus on the interactions, "we enter a hall of mirrors that extends to infinity" (Cronbach 1975: 119). In the future we will also need to compare case pedagogy with other teacher education strategies and other instructional materials. Following the suggestions by Fenstermacher (1994) and Merseth and Lacey (1993), researchers will have to think very carefully about the intended outcomes of case pedagogy and the research objectives. In addition, it is central to bear in mind that the relationship between the purpose, use, and outcome of case pedagogy varies considerably. In their 1992 review article of the case idea, Sykes and Bird stated that the "future of the case idea, we suspect, rests more on development than research, or perhaps on research in the context of development. We mean that the central task ahead is to create and use rich and interesting case materials in a variety of settings for a variety of purposes, while simultaneously studying those uses" (Sykes and Bird 1992: 509). They also suggested that case pedagogy should be compared with other teacher education strategies and materials. Merseth (1996: 739) pointed out that prior to the undertaking of such studies it was necessary to clarify the intended outcomes of case use. "Are they looking for effects on teacher cognition, on teacher behavior in classrooms, or on personal beliefs and feelings?" She further suggested three general lines of research, which we still consider valid:

- Research on case materials design for teacher education and their impact.

- Research on different practical approaches to case pedagogy. This strand of research should seek to explore issues of curriculum, variations in pedagogy, sequence within teacher education programmes, and teacher educator characteristics.

- Research on the influence of students' characteristics on learning from cases.

Finally, we would like to stress that the significance of research on case pedagogy is greatly dependent on the actual development of cases on the basis of teacher experience. Paradoxically, the development of cases is a very complex and timeconsuming process but it is not usually acknowledged as "research" by the profession. As we hope to illustrate in the two following chapters, case construction by teachers and teacher educators can become a form of pedagogical research that requires and promotes the ability to take a critical stance towards education and educational contexts, to frame relevant pedagogical problems, to interrogate and reshape dominant practices through inquiry-oriented action plans, to theorise action taken in the light of (personal and public) theories and classroom data, and to narrate educational experience in a coherent and reflective way. What we are suggesting here is that case pedagogy can be much more than a teacher education method. As a form of pedagogical research, it can also become a method for inquiring into school pedagogy and for developing a scholarship of 
teacher education. This should make policy-makers and teacher educators alike reconsider their stance towards what counts as research in the teacher education profession.

\section{Concluding remarks}

L. Shulman (1992: 1) states that "case methods are expected to be more engaging, more demanding, more intellectually exciting and stimulating, more likely to bridge the apparently unbreakable division between principle and practice, and more likely to help novices to learn to think like a teacher." However, as Remillard (2000: 71) holds, “cases are not a panacea." Like other teacher education tools they do not stand alone, they need to be supplemented with other material and teacher education strategies. Multiple factors influence teacher learning - using cases alone in teacher education is no guarantee of learning. Furthermore, we need to be alert to the potential risks of using personal narratives as learning tools that may limit rather than expand a critical view of education. As Tochon (1994: 241) points out, “There is no absolute in the story nor in story making; action takes precedence. There are just interpretative processes, slips and slides of meaning. Just language in motion. Thus narrative creates the delusion of manipulable knowledge and meaning, and it may prevent the individual from finding his/ her own ultimate implication." This is why it is crucial to link story to experience and use multiple frames of reference to analyse and write cases. Provided that an inquiry stance is developed in case pedagogy, we tend to go along with L. Shulman (2004a: 543-544) when he argues that cases can become the lingua franca of teacher learning communities:

Cases are ways of parsing experience so practitioners can examine and learn from it. Case methods thus become strategies for helping professionals 'chunk' their experience into units that can become the focus for reflective practice. Cases therefore can become the basis for individual professional learning as well as a forum within which communities of professionals (...) can store, exchange and organize their experiences. They may well become, for teacher education, the lingua franca of teacher learning communities.

While the arguments for adopting case-based pedagogy in teacher education are rich and powerful, there are still many unanswered questions about the nature of case-based pedagogy in teacher education for learner autonomy. As Grossman (1992: 227) puts it: "our enthusiasm for a new method that promises to link theory and practice in a way that engages students cannot overshadow the need to understand more about what students are actually learning when we teach with 
cases or to examine the potential pedagogical pitfalls in using case methods." Nevertheless, on the basis of our own experience as teacher educators working with cases, we can hold that case pedagogy can be very valuable for prompting teachers to consider issues of autonomy, introducing them to alternative pedagogies. As will be illustrated in the following chapters, we have found evidence to argue that cases tend to enrich teachers' analyses of key questions and critical issues by representing them in their full complexity. Moreover, they steer teachers into the processes of examining and reshaping their deeply held beliefs, scrutinising their own practices and generating actions that are more humanistic and democratic. 